\title{
Formation and Simulation of Cutting Direction Fracture
}

\author{
H. J. Qu ${ }^{1 a}$, J.H. Yang ${ }^{1 b}$, G.C. Wang ${ }^{2 c}$ \\ ${ }^{1}$ School of Mechanical and Power Engineering, Henan Polytechnic University, Henan, China \\ ${ }^{2}$ School of Mechanical Engineering, Jiangsu University, Zhenjiang 212013, China \\ aquhaijun006@126.com, byangjinhua@hpu.edu.cn, cwgch@ujs.edu.cn
}

\begin{abstract}
Keywords: cutting direction fracture; negative shear zone; FEM; crack
Abstract. Cutting-direction fracture is one of the most common and undesirable phenomenon occurring in machining operations that reduces assembly and machined part quality, and it should be avoided or at least reduced.. A finite element model has been established to investigate the mechanism of cutting direction fracture formation in machining H64 brass. Based on stress distribution, a cutting direction fracture formation mechanism was proposed and divided into five stages: normal cutting stage, pivoting stage, crack initiation stage, crack growth stage and fracture formation stage. The cutting direction fracture forms when there is a crack in the area near the tool tip and grow along the negativel shear zone.
\end{abstract}

\section{Introduction}

With the rapid development of manufacturing science and technology, the mechanical machining technology is developing toward the high precision and high efficiency machining. Cutting direction fracture often form on edges of metal workpiece, the existence of fracture reduces machining accuracy, increases machining cost, and influences performance of parts. The existence of fracture has become one of the key problems that influence the development of automatic machining, flexible process and precise manufacturing. Since the 1980's, many scholars have conducted much study work with experimental and theoretical methods and some achievements have been obtained [1-6]. However, the forming process of cutting direction fracture is influenced by many factors; it is very difficult to obtain precision analytical solution for general problems with large deformation such as chip and fracture formation processes. Using the FEM to simulate the burr fracture processes is a reasonable approach. Based on FEM simulation results and experimental tests fracture formation process is analyzed in this paper.

\section{The Finite Element Model}

The geometrical model is shown in fig.1, the material is brass $(\mathrm{H} 64: 65 \% \mathrm{Cu}, 35 \% \mathrm{Zn})$ and its stress-strain behavior is taken as [7]:

$\bar{\sigma}=c \bar{\varepsilon}^{n}$

Where, $\bar{\sigma}$ is effective stress, $\bar{\varepsilon}$ is effective strain, $\mathrm{b}$ is material constant, $\mathrm{n}$ is strain harding coefficient.

Cockroft\&Latham criterion is chosen [8]. The friction state is treated as shearing friction [9].

\section{Simulation Results and Discussions}

Based on a series of stress contours the progressive change of geometry at the edge of workpiece edge from simulation, a cutting direction fracture formation mechanism is proposed and divided into five stages as shown in Fig.2: normal cutting stage, pivoting stage, crack initiation stage, crack growth stage and fracture formation stage.

Normal Cutting. Chip flows along the rake face favorably under this stage. Workpiece layer under cutting deforms along the principal shear zone where shear stress value is maximum. The boundary of three shear zone is obviously seen in simulation results, as shown in Fig.2(a). As a result, the chip forms in front of the cutting tool.

Pivoting Stage. With the advancement of the cutting tool towards workpiece edge, the plastic zone extends toward the edge, negative shear starts to form. The shear angle and the principal shear 
zone become smaller and smaller. The end part of workpiece begins to deforming around point 'A'. Materials begin to flow along negative shear zone, as shown in Fig.2 (b).

Crack Initiation. With further advancement of the cutting tool, parts of materials that have been cut slip along the negative shear zone under the effect of cutting force. The actual cutting thickness is larger than the theory cutting thickness, cutting force increases and the shear stress around the tool tip becomes larger, the tensile strength of materials around tool tip is not sufficient which lead to cracks generation, as shown in Fig.2(c).

Crack Growth. With the generation of cracks around the tool tip and expansion of cracks along the direction of negative shear zone as stress in negtive shear zone is greater than it in principal shear zone, the difference between the actual cutting thickness and the theory cutting thickness becomes larger, cutting force further increases which lead to the cracks expansion further more inturn, as shown in Fig.2(d).

Fracture Formation. As the tool approaches the workpiece edge, cracks expand at the same time. Chip rotates around the pivot which locates on the edge of workpiece under the push effect of cutting tool. Chip separates from the workpiece due to breaking finally. Fracture forms on the workpiece edge in cutting-direction, as shown in Fig.2 (e).

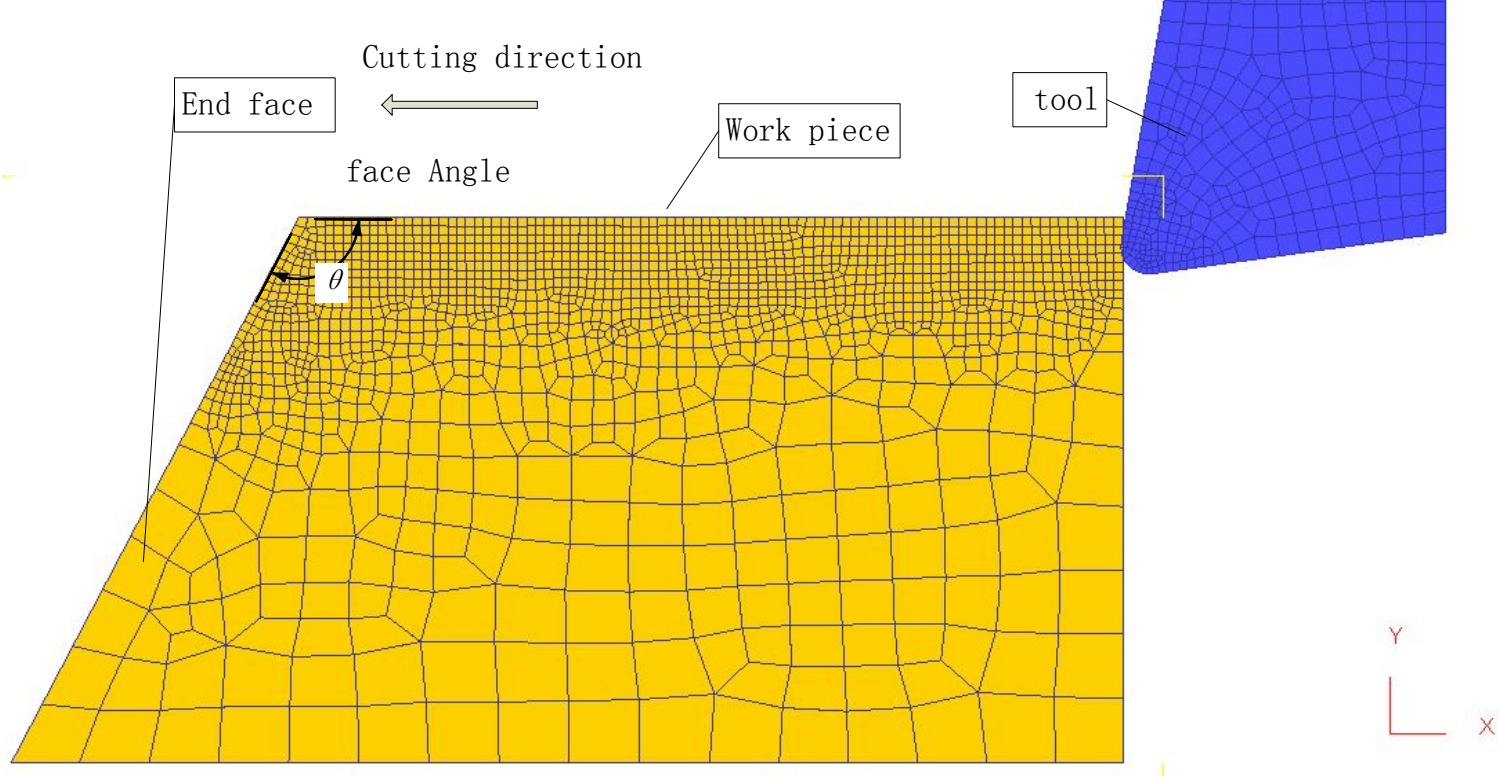

Fig. 1 Finite element model for fracture formation
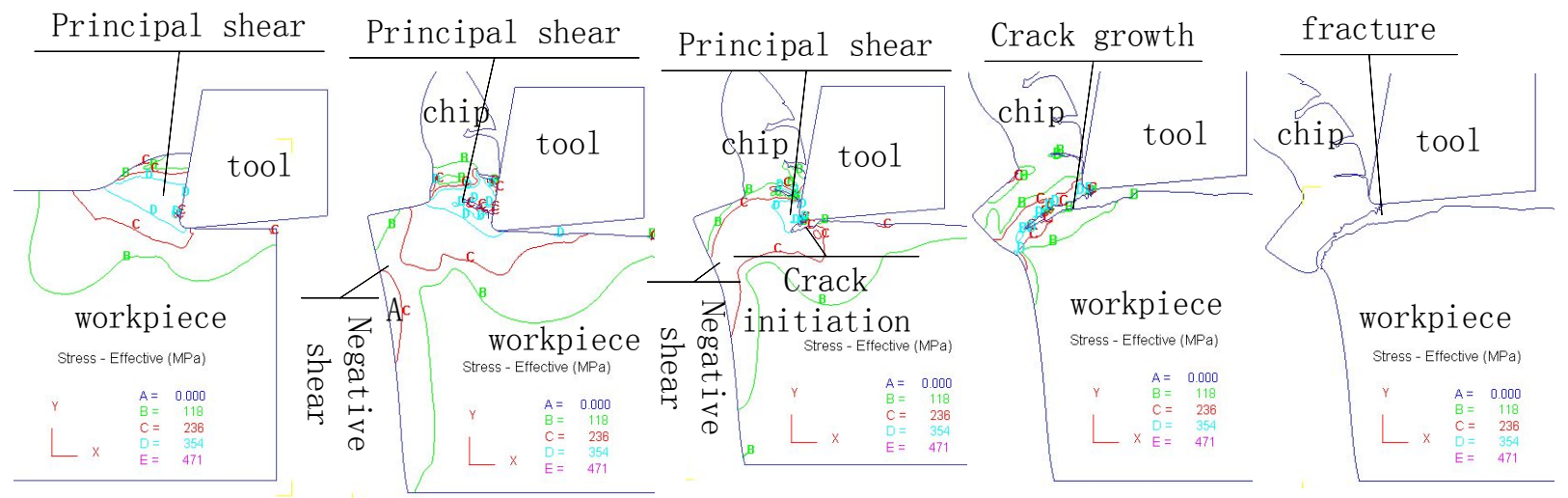

(a) Normal cutting (b) Pivoting Stage (c) Crack initiation (d) Crack growth (e) Fracture formation Fig. 2 forming process of cutting direction fracture 


\section{Experiment Setup and Cutting Conditions}

To verify the simulation results and burr formation process, metal cutting experiment carried out on the refitted milling machine. Table 1 shows the cutting conditions and tool geometries in the experiment. Cutting conditions parameters which has underline are standard experimental parameters. The size of $\mathrm{H}_{2}$ and $\mathrm{B}_{2}$ in Fig.3 are studied in this paper.

\begin{tabular}{|l|c|}
\cline { 2 - 2 } \multicolumn{1}{l|}{ Table 1 cutting conditions and tool geometries [1] } \\
\hline Cutting speed $[\mathrm{mm} / \mathrm{min}]$ & $\underline{2}$ \\
\hline depth of cut $[\mathrm{mm}]$ & $0.05 \sim 0.3 \underline{0.10}$ \\
\hline Rake angle $\left.{ }^{\circ}\right]$ & $30 ; 20 ; \underline{10 ; 0}$ \\
\hline Tool edge radius $[\mu \mathrm{m}]$ & $20 ; \underline{40 ; 60}$ \\
\hline Workpiece edge angle $\psi\left[^{\circ}\right]$ & $\underline{90}$ \\
\hline
\end{tabular}

\section{Experimental and simulation Results}

Fig. 4 and Fig. 5 shows the effect of the cutting depth and tool edge radius on fracture thickness $\mathrm{B}_{2}$ and fracture height $\mathrm{H}_{2}$ respectively. As the cutting depth increased, both fracture thickness and fracture height increased. As the tool edge radius increased, both fracture thickness and fracture height decreased

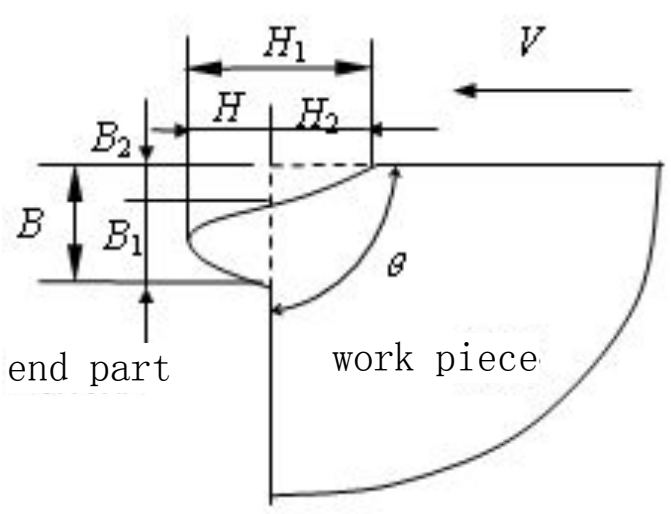

(a)

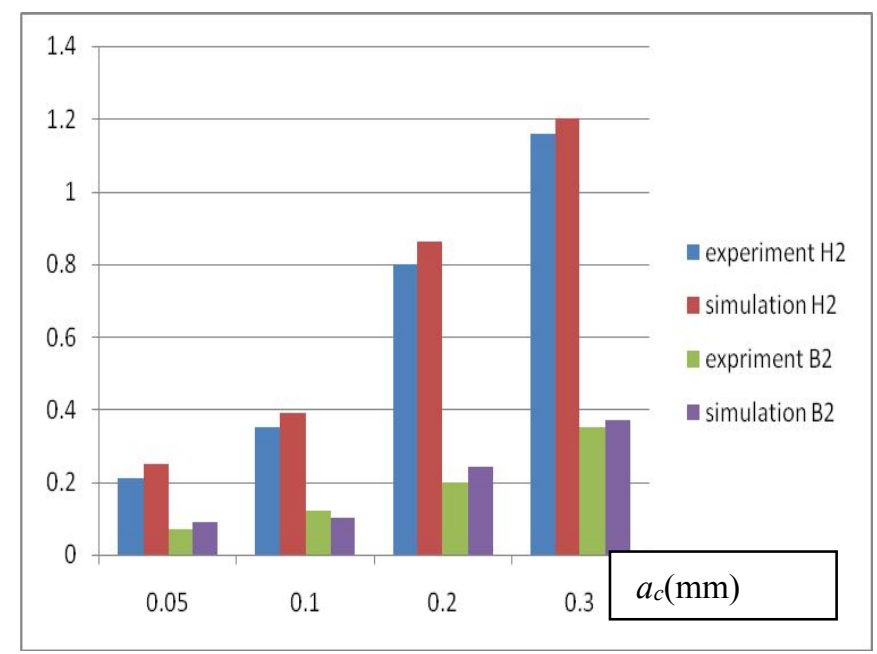

Fig.4 Effect of cutting depth on fracture size

Fig. 3 the shape of end part after cutting

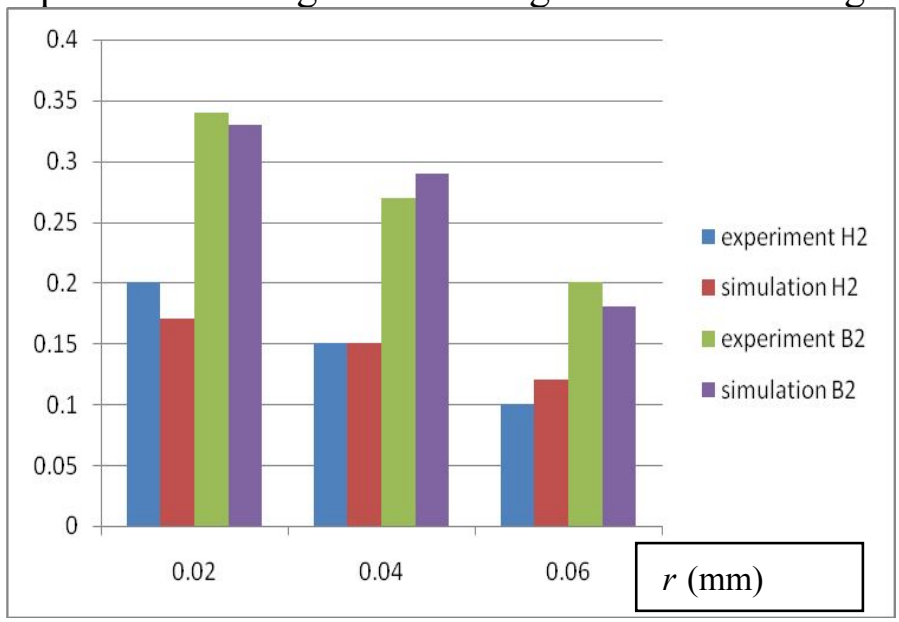

Fig. 5 Effect of edge radius on fracture size 


\section{Conclusions}

A finite element model of cutting direction fracture formation process is established. From the simulation results of stress distribution, the mechanism of the fracture formation process is analyzed. Finite element model generated here provided a numerical analysis method to solve the problem of fracture formation and physical insight into the fundamental fracture formation mechanism.

Simulation results and experimental results have been compared; simulation results are consisting with experimental results. It comes to conclusion that generation of negative shear zone is reason for burr formation.

It is shown that decrease the cutting depth and increase tool edge radius can control the size of fracture.

\section{Acknowledgements}

The authors would like to thank Dr Found (No: 2012-054). The paper is Supported by the Opening Project of Key Laboratory of Precision Manufacturing technology and engineering, Henan Polytechnic University (No: PMTE201311A)

\section{References}

[1] G. C. Wang: Metal cutting burrs. (Jilin Press of science and technology, Jilin, 1997.11).

[2] Y. M. Zhu: Study on Formation and controlling of Metal cutting Burr and Development of Burr Expert System. (Ph. D. Jiangsu University 2006).

[3] G. L. Chern. D. A. Donfeld: Burr/Breakout Model Development and Experiment Verification, Journal of Engineering Materials and Technology. vol. 118 (1996), P 201 206.

[4] I. W. Park. D. A. Donfeld: A Study of Burr Formation Process Using the Finite Element Method: Part (II), Journal of Engineering Materials and Technology.( 2000), 122, P.229 237.

[5] Q.X.Shen, G.C.Wang, Y.M.Zhu, et al: Transformation of Cutting Burr/Fracture in High Speed Machining Al-Alloy. Advanced Materials Research. Vols.53-54 (2008): 101-107

[6] K.Z.K Iwata, K.J. Ueda and K.C. Okuda: Study of Mechanism of burr Formation in cutting Based on Direct SEM Observation. (1982), P.94 99.

[7]Zhao Zhude, Yao Liangjun, Peng Ruqing. Handbook of Copper and copper alloy [M].Beijing: Press of science and technology, 1993 (in Chinese)

[8] M. G. Cockroft: Determinnattion of workpice flow stress and friction at chip-tool contact for high-speed cutting. International Journal of Machine Tools \& Manufacture, (2000), P.133 152.

[9] N. N. Zorev: Inter-relationship between shear processes occurring along tool face and shear plane in metal cutting, Proceedings of International Research in Production Engineering, ASME, New York.(1963)P42 49. 